\title{
Remdesivir for the treatment of patients in hospital with COVID-19 in Canada: a randomized controlled trial
}

\author{
Canadian Treatments for COVID-19 (CATCO)*; for the Association of Medical Microbiology and Infectious \\ Disease Canada (AMMI) Clinical Research Network and the Canadian Critical Care Trials Group
}

${ }^{\star}$ The complete list of authors appears at the end of the article.

Cite as: CMAJ 2022 February 22;194:E242-51.doi: 10.1503/cmaj.211698; early-released January 19, 2022

\begin{abstract}
Background: The role of remdesivir in the treatment of patients in hospital with COVID-19 remains ill defined in a global context. The World Health Organization Solidarity randomized controlled trial (RCT) evaluated remdesivir in patients across many countries, with Canada enrolling patients using an expanded data collection format in the Canadian Treatments for COVID-19 (CATCO) trial. We report on the Canadian findings, with additional demographics, characteristics and clinical outcomes, to explore the potential for differential effects across different health care systems.
\end{abstract}

Methods: We performed an open-label, pragmatic RCT in Canadian hospitals, in conjunction with the Solidarity trial. We randomized patients to 10 days of remdesivir (200 mg intravenously [IV] on day 0 , followed by $100 \mathrm{mg}$ IV daily), plus standard care, or standard care alone.
The primary outcome was in-hospital mortality. Secondary outcomes included changes in clinical severity, oxygen- and ventilator-free days (at $28 \mathrm{~d}$ ), incidence of new oxygen or mechanical ventilation use, duration of hospital stay, and adverse event rates. We performed a priori subgroup analyses according to duration of symptoms before enrolment, age, sex and severity of symptoms on presentation.

Results: Across 52 Canadian hospitals, we randomized 1282 patients between Aug. 14, 2020, and Apr. 1, 2021, to remdesivir $(n=634)$ or standard of care $(n=$ 648). Of these, 15 withdrew consent or were still in hospital, for a total sample of 1267 patients. Among patients assigned to receive remdesivir, in-hospital mortality was $18.7 \%$, compared with $22.6 \%$ in the standard-of-care arm (relative risk [RR] 0.83 (95\% confidence interval [Cl] 0.67 to 1.03 ), and 60 -day mortality was
$24.8 \%$ and $28.2 \%$, respectively $(95 \% \mathrm{Cl}$ 0.72 to 1.07 ). For patients not mechanically ventilated at baseline, the need for mechanical ventilation was $8.0 \%$ in those assigned remdesivir, and $15.0 \%$ in those receiving standard of care (RR $0.53,95 \% \mathrm{Cl}$ 0.38 to 0.75$)$. Mean oxygen-free and ventilator-free days at day 28 were 15.9 ( \pm standard deviation [SD] 10.5) and 21.4 ( \pm SD 11.3) in those receiving remdesivir and $14.2( \pm$ SD 11$)$ and $19.5( \pm$ SD 12.3) in those receiving standard of care $(p=0.006$ and 0.007 , respectively). There was no difference in safety events of new dialysis, change in creatinine, or new hepatic dysfunction between the 2 groups.

Interpretation: Remdesivir, when compared with standard of care, has a modest but significant effect on outcomes important to patients and health systems, such as the need for mechanical ventilation. Trial registration: ClinicalTrials.gov, no. NCT04330690.

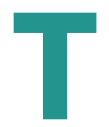
he role of remdesivir in treating patients in hospital with COVID-19 remains ill defined. ${ }^{1}$ Remdesivir, a repurposed antiviral medication, has full or emergency approval from a number of regulators - including Health Canada - for the treatment of COVID-19, based on clinical trial data documenting a benefit on improving time to recovery. ${ }^{2}$ An interim report of the larger World Health Organization (WHO) Solidarity trial showed no difference regarding mortality or need for mechanical ventilation, with a number of smaller trials being inconclusive on these important outcomes. ${ }^{3-6}$ Recommendations of clinical guidelines are mixed, with some recommending remdesivir as standard of care, and others weakly recommending against. ${ }^{7,8}$ Its impact on other clinical outcomes, including resource utilization and post-hospital stay outcomes, has not been fully defined, and there remains a possibility of an important treatment effect, particularly in certain groups of patients. ${ }^{9}$ 
Solidarity is a global pragmatic clinical trial examining the effects of various therapeutics in patients with COVID-19. ${ }^{3,10}$ Canadian Treatments for COVID-19 (CATCO) is a substudy of Solidarity, funded by the Canadian Institutes of Health Research (CIHR), in which added data elements are collected to better understand the effects of specific agents. We aimed to estimate the effect of treatment with remdesivir compared with standard care, for patients in hospital with COVID-19 in Canada; global data, which include Canadian patients randomized before Jan. 29, 2021, will also be available in a separate publication.

\section{Methods}

CATCO is a pragmatic, multicentre randomized controlled trial (RCT), in which multiple agents are compared against the currently available standard of care in an open-label fashion. Eligible patients include adults admitted to participating hospitals (Appendix 1, available at www.cmaj.ca/lookup/doi/10.1503/ cmaj.211698/tab-related-content) with laboratory-confirmed SARS-CoV-2 infection. Exclusion criteria were allergy to study drug, anticipated transfer to a nonstudy site, expected to not survive beyond 24 hours, or already receiving remdesivir at time of enrolment. Baseline renal or hepatic dysfunction were not specific exclusion criteria. The effect of other drugs studied in CATCO - interferon, lopinavir-ritonavir and hydroxychloroquine - are reported as part of a previous Solidarity interim report. ${ }^{3}$

We randomized eligible and consenting patients to either the intervention treatment regimen of remdesivir (intravenous [IV]) $200 \mathrm{mg}$ on day 0 and $100 \mathrm{mg}$ on days 1 through 9 plus standard care, or the control treatment regimen, consisting of standard care. All other care decisions were left to the treating clinicians, including co-interventions, such as dexamethasone or tocilizumab or both for eligible patients, according to time period, hospital setting and participation in other RCTs. ${ }^{11}$ Patients were discharged when the treating team deemed them clinically eligible, and study intervention was stopped if discharge occurred before completion of a full course of treatment. Consent was either obtained a priori or deferred, as per the requirements of local ethics boards. We randomized patients, unstratified, in a 1:1 ratio. After the Solidarity initial interim analysis was reported, recruitment preferentially focused on patients who were not mechanically ventilated. ${ }^{3}$ We performed randomization through the global Solidarity trial until Jan. 29, 2021, and then in Canada until Apr. 1, 2021, through a Web-based server after Solidarity ceased randomization to remdesivir. As such, CATCO enrolled more Canadian patients than are included in the global Solidarity trial, all using the same unstratified randomization ratios.

\section{Outcome measures}

The primary outcome in the global Solidarity trial was in-hospital mortality, with secondary outcomes of new need for mechanical ventilation (for those not ventilated at baseline) and hospital length of stay. ${ }^{3}$ Additional predefined secondary outcomes for CATCO included in this report were clinical severity of illness on days 3, 5, 8, 11, 15, 29 and 60 (including postdischarge), according to the WHO Ordinal Scale; ${ }^{12}$ oxygen-free and ventilator-free days at day 28 from time of randomization, defined as 0 if the patient died within 28 days and 28 minus number of days with oxygenation or ventilation, respectively; ${ }^{13}$ and safety outcomes of special interest, including new hepatic dysfunction and new need for renal replacement therapy. We did not conduct a prespecified exploratory analysis of the proportion of patients with negative viral swabs at various time points after randomization, given the amount of missingness in this data point.

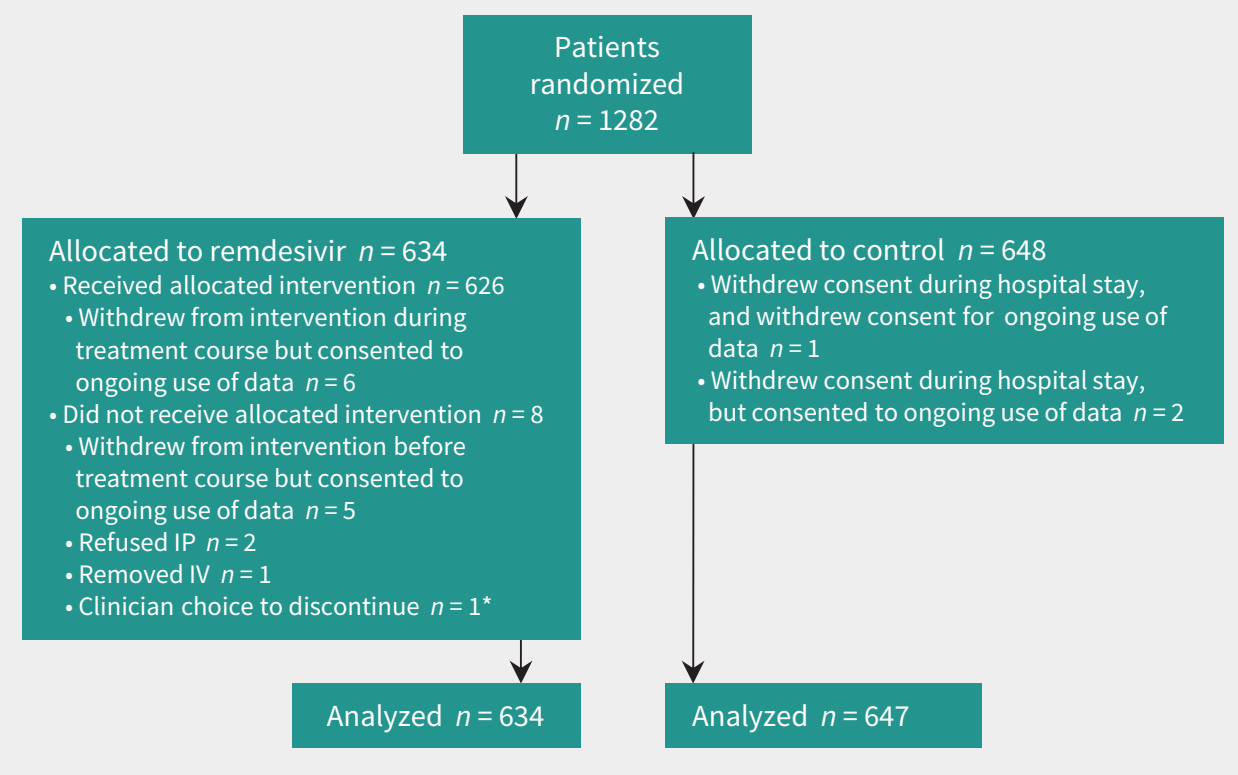

Figure 1: Flow chart showing enrolment, randomization and inclusion of patients in analysis. Note: IP = investigational product, IV = intravenous. ${ }^{*}$ One patient with 2 reasons. 
Statistical analysis

Among patients in the CATCO trial, we report the primary outcome, as well as the 2 secondary Solidarity outcomes, in addition to the above-listed secondary outcomes. The primary analysis was based upon intention to treat. We report all-cause mortality and the binary secondary outcomes as proportions, risk ratios, absolute risk difference and $95 \%$ confidence intervals (Cls). We examined secondary outcomes of clinical severity using

\section{Table 1: Characteristics of patients at baseline in the Canadian Treatments for COVID-19 trial}

\section{Characteristic}

Age, yr, median (IQR)

Female sex

Clinical Frailty Score, median (IQR)

Time from symptom onset, to hospital admission, d, median (IQR) $(n=1210)$

Time from hospital admission to symptom onset for nosocomial acquisition ( $n=65)$, d, median (IQR)

Time from symptom onset to randomization, $d$, median (IQR)

Diabetes $\dagger$

Chronic respiratory disease $\dagger$

Asthma†

Smoker†

Chronic cardiovascular disease $\dagger$

Chronic liver disease ${ }^{\dagger}$

HIV positive $\dagger$

Ethnic group $\ddagger$

White

South Asian

East Asian

Indigenous or First Nations

Black

Arab

Latin American

West Asian

Other

Not available

Employed as a health care worker

Corticosteroid use

Tocilizumab use

Baseline severity at randomization

Patient in ICU

Organ support on day 0

No organ support

Low-flow oxygen

High-flow nasal oxygen

Noninvasive ventilation

Invasive mechanical ventilation

\section{No. $(\%)^{\star}$ of patients receiving remdesivir $n=634$}

\section{5 (53 to 77 )}

260 (41.0)

3 (3 to 5 )

6 (3 to 9 )

16 (7 to 40$)$

8 (5 to 11$)$

155 (33.6)

67 (14.5)

49 (10.6)

$23(5.0)$

$120(26.0)$

$8(1.7)$

$1(0.2)$

269 (42.4)

$90(14.2)$

$40(6.3)$

$40(6.3)$

20 (3.2)

22 (3.5)

23 (3.6)

8 (1.3)

$9(1.4)$

119 (18.8)

$29(4.6)$

$553(87.2)$

$14(2.2)$

139 (21.9)

71 (11.2)

$334(52.7)$

149 (23.5)

22 (3.5)

58 (9.1)
No. $(\%)^{\star}$ of patients receiving standard of care $n=647$

66 (54 to 77$)$

255 (39.4)

3 (2 to 5 )

6 (4 to 9$)$

$8(5$ to 16.5$)$

8 (6 to 11$)$

$188(38.4)$

65 (13.3)

55 (11.2)

$22(4.5)$

$135(27.6)$

19 (3.9)

$1(0.2)$

255 (39.4)

$110(17.0)$

42 (6.5)

$28(4.3)$

25 (3.9)

24 (3.7)

21 (3.2)

12 (1.9)

14 (2.2)

$126(19.5)$

$28(4.3)$

564 (87.2)

$5(0.8)$

135 (20.9)

363 (56.2)

153 (23.7)

23 (3.6)

$54(8.3)$

Note: ICU = intensive care unit, IQR = interquartile range.

*Unless otherwise specified.

†All the unavailable, unknown and missing values were set to "No." Data on these comorbidities are available for a subset of patients: $n=951$ ( $n=461$ in remdesivir and $n=490$ in control group).

$\ddagger$ Percentages add to more than $100 \%$ as multiple ethnic groups might have been chosen. 
a proportional odds model, adjusting for baseline severity based on ordinal scale position at baseline. The proportionality assumption for clinical severity outcomes did not hold for some outcomes and we therefore compared groups using a Wilcoxon rank-sum test. We used the Fine-Gray model to compare the time to discharge alive, accounting for competing risk of death, and present results as subdistribution hazards and $95 \% \mathrm{Cl}$. We summarize duration of hospital stay and oxygenfree and ventilator-free days using means and standard deviations (SDs), and medians and interquartile ranges (IQRs); differences between the groups for medians and 95\% $\mathrm{Cls}$ are based on the Hodges-Lehman approach. Subgroup analyses for the primary outcome of mortality evaluated the treatment effect across the following prespecified subgroups, with tests for interaction: duration of symptoms before enrolment $(<7 \mathrm{~d})$, age younger than 55 years, sex, and severity of symptoms on presentation (defined as amount of respiratory support, including low-flow oxygen, high-flow nasal oxygen, noninvasive ventilation and invasive mechanical ventilation). There was no imputation for missing data. Given that this study was part of a global adaptive trial, we did not perform power calculations. $P$ values less than 0.05 denote statistical significance for primary and secondary outcomes, which were not adjusted for multiplicity. We performed all statistical analyses in SAS (version 9.4, Cary, NC).

\section{Ethics approval}

This study was approved by local research ethics boards and coordinated by Sunnybrook Research Institute. The trial was conducted in accordance with the principles of the Guideline for Good Clinical Practice of the International Council for Harmonization (http://www.ich.org).

\section{Results}

Between Aug. 14, 2020, and Apr. 1, 2021, we randomized 1282 patients between remdesivir $(n=634)$ and standard of care $(n=648$ ) (Figure 1 ) at 52 Canadian hospitals (Appendix 1, Table S2). Of these, outcome data were missing for 15 patients -9 because consent was withdrawn and 6 were still in hospital at time of analysis - for a total sample size of 1267 for the primary mortality outcome. This article includes 951 patients who will be described in the global Solidarity report.

\section{Baseline characteristics}

Table 1 shows patient characteristics at baseline. Reflecting the demographic profile of patients in hospital during this pandemic in Canada, there was a sizable proportion of racialized people and those with pre-existing comorbid conditions. Baseline corticosteroid use, which was the standard of care for patients in hospital and on oxygen during most of this trial period, was similar

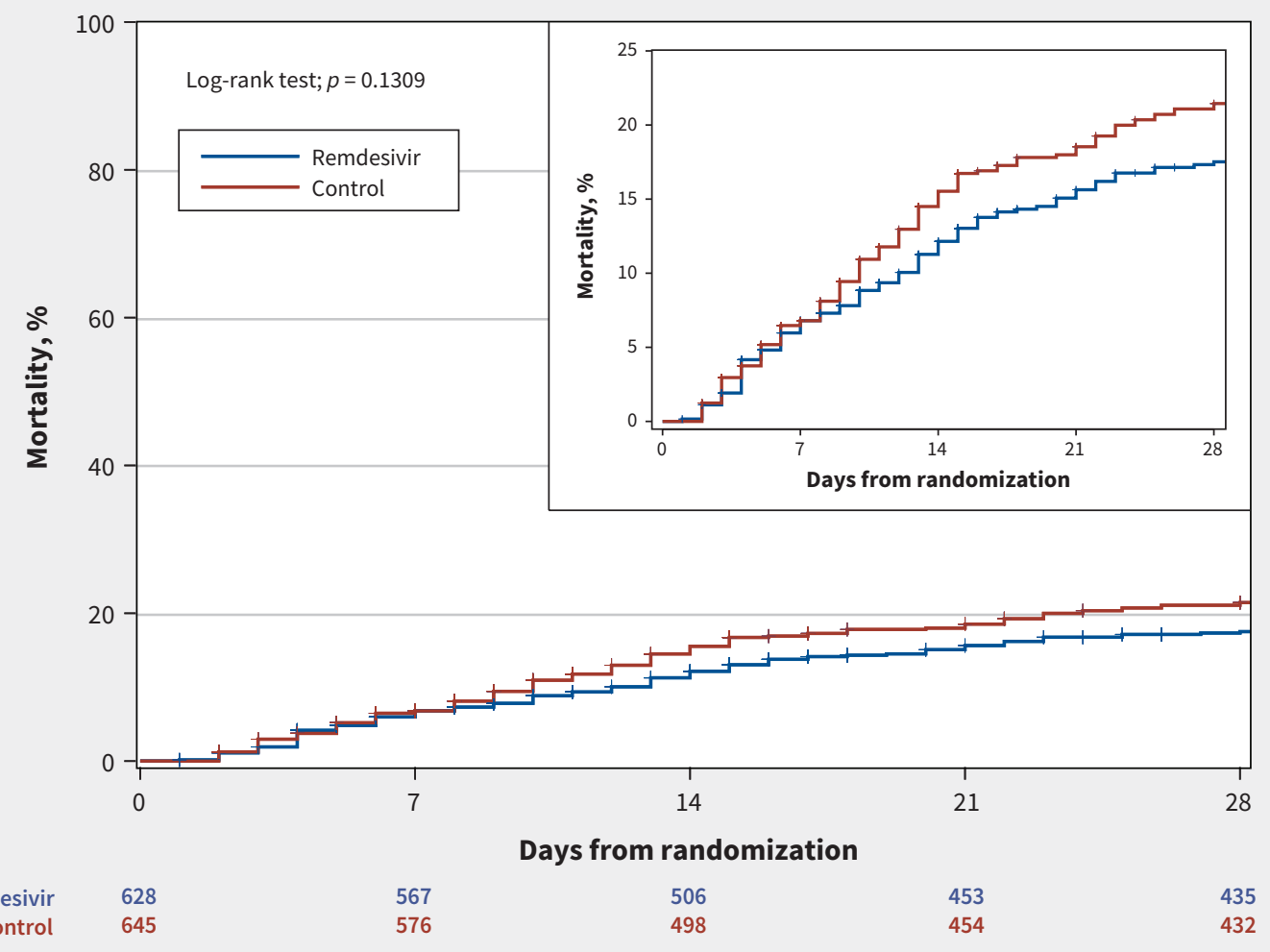

Figure 2: Days from randomization to mortality: censored at hospital discharge, 15 or $29 \mathrm{~d}$, whichever is observed last. Note: $\mathrm{Cl}=$ confidence interval, $\mathrm{HR}=$ hazard ratio. 
across groups. Treatment with tocilizumab was low (1.5\%), consistent with evolving practice patterns in Canadian hospitals. Most patients were on low-flow oxygen (54.5\%) on day 1 , and $21.4 \%$ were in the intensive care unit (ICU) at time of randomization. There were 57 health workers and 1 pregnant patient enrolled in the trial.

\section{Outcomes}

Among patients assigned to receive remdesivir, in-hospital mortality was $18.7 \%$, compared with $22.6 \%$ in the standard of care arm (relative risk [RR] 0.83, 95\% Cl 0.67 to 1.03) (Appendix 1, Supplemental Figure S1 and Supplemental Table S3), and 60-day mortality was $24.8 \%$ and $28.2 \%$, respectively (RR $0.88,95 \% \mathrm{Cl}$ 0.72 to 1.07 ). For patients not mechanically ventilated at baseline, the need for mechanical ventilation was $8.0 \%$ in those assigned remdesivir and $15.0 \%$ in those assigned to standard of care (RR $0.53,95 \% \mathrm{Cl} 0.38$ to 0.75 ). Mean oxygen-free and ventilator-free days at day 28 were $15.9( \pm$ SD 10.5) and $21.4( \pm$ SD $11.3)$ in those receiving remdesivir and 14.2 ( \pm SD 11) and 19.5 ( \pm SD 12.3) in those receiving standard of care $(p=0.006$ and 0.007 , respectively). Duration of hospital stay was not different between the 2 groups (median 10 [IQR 6-18] in the remdesivir group v. 9 [IQR 6-17] in the control group, Figure 2), and we observed no difference in duration of hospital stay for survivors (Table 2).

Examining in-hospital mortality among prespecified subgroups, the treatment effect did not vary according to age, sex, severity of disease or duration of symptoms (Figure 3).

Clinical recovery, as measured by position on the WHO Ordinal Scale, is reported in Table 3, and day 15 status in Figure 4.

\section{Safety}

There were no differences in secondary safety outcomes between intervention groups in serum creatinine on day 5 , incidence of new dialysis or incidence of hepatic dysfunction (Table 2).

\section{Table 2: Clinical outcomes of patients in the Canadian Treatments for COVID-19 trial}

\begin{tabular}{|c|c|c|c|c|}
\hline In-hospital mortality, $n=1267 \dagger$ & $117(18.7)$ & $145(22.6)$ & $\begin{array}{c}0.83 \\
\text { (0.67 to } 1.03)\end{array}$ & $-3.9(-8.3$ to 1.03$)$ \\
\hline Need for new mechanical ventilation, $n=1168 \S$ & $46(8.0)$ & $89(15.0)$ & $\begin{array}{c}0.53 \\
(0.38 \text { to } 0.75)\end{array}$ & $-7.0(-10.6$ to -3.4$)$ \\
\hline Duration of hospital stay $†$ median (IQR) & 10 (6 to 18$)$ & $9(6$ to 17$)$ & $0(-1$ to 0$)$ & \\
\hline Duration of hospital stay for survivors, median (IQR); $n=1005$ & $9(6$ to 17$)$ & $9(6$ to 16$)$ & $0(-1$ to 0$)$ & \\
\hline Oxygen-free days at day 28, mean $\pm S D,{ }^{\star \star}$ median (IQR); $n=1168$ & $\begin{array}{l}15.9 \pm 10.5 \\
20(0 \text { to } 24)\end{array}$ & $\begin{array}{l}14.2 \pm 11.1 \\
19(0 \text { to } 24)\end{array}$ & $\begin{array}{c}1.7(0.4 \text { to } 3.0) \\
0(-1 \text { to } 0)\end{array}$ & \\
\hline Ventilator-free days at day 28 , mean $\pm \mathrm{SD},{ }^{\star *}$ median (IQR); $n=1168$ & $\begin{array}{c}21.4 \pm 11.3 \\
28(19 \text { to } 28)\end{array}$ & $\begin{array}{l}19.5 \pm 12.3 \\
28(1 \text { to } 28)\end{array}$ & $\begin{array}{c}1.9(0.5 \text { to } 3.2) \\
0(0)\end{array}$ & \\
\hline \multicolumn{5}{|l|}{ Safety } \\
\hline New hepatic dysfunction†† & $82(13.1)$ & $88(13.7)$ & $\begin{array}{c}0.96 \\
(0.72 \text { to } 1.26)\end{array}$ & $-0.6(-4.4$ to 3.1$)$ \\
\hline New dialysis $\ddagger ; n=1265$ & $16(2.6)$ & $15(2.3)$ & $\begin{array}{c}1.09 \\
\text { (0.54 to } 2.19)\end{array}$ & $0.2(-1.5$ to 1.9$)$ \\
\hline Day 5 serum creatinine, mean \pm SD; median (IQR); $n=936$ & $\begin{array}{c}86.7 \pm 78.0 \\
71(57-88.5)\end{array}$ & $\begin{array}{c}87.7 \pm 79.2 \\
69(57-87.5)\end{array}$ & $\begin{array}{c}-0.92 \\
(-10.9 \text { to } 9.1) \\
-1(-4 \text { to } 2)\end{array}$ & \\
\hline
\end{tabular}




\begin{tabular}{|c|c|c|c|c|c|c|c|}
\hline \multirow[b]{3}{*}{ Subgroup } & \multirow[b]{3}{*}{ No. $(\%)$ of patients } & \multicolumn{3}{|c|}{ Hospital death rate } & \multirow{3}{*}{$\begin{array}{r}\text { Favours } \\
\text { remdesivir }\end{array}$} & \multirow{3}{*}{$\begin{array}{l}\text { Favours } \\
\text { control }\end{array}$} & \\
\hline & & \multicolumn{2}{|c|}{ Group } & \multirow[b]{2}{*}{$p$ value } & & & \\
\hline & & Remdesivir & Control & & & & \\
\hline Overall & $1267(100)$ & $117 / 625(19)$ & $145 / 642(23)$ & & $\rightarrow$ & & \\
\hline Age & & & & 0.68 & & & \\
\hline$<55 \mathrm{yr}$ & $331(26)$ & $6 / 166(4)$ & $6 / 165(4)$ & & & & \\
\hline$\geq 55 \mathrm{yr}$ & $936(74)$ & $111 / 459(24)$ & 139/477 (29) & & & & \\
\hline Sex & & & & 0.81 & & & \\
\hline Male & $756(60)$ & $77 / 368(21)$ & $99 / 388(26)$ & & & I & \\
\hline Female & $510(40)$ & $40 / 257(16)$ & $46 / 253(18)$ & & & & \\
\hline Respiratory support day 1 & & & & 0.41 & & & \\
\hline No oxygen therapy & $122(10)$ & $7 / 68(10)$ & $8 / 54(15)$ & & & & \\
\hline Oxygen therapy & $690(55)$ & $36 / 330(11)$ & $58 / 360(16)$ & & $\longrightarrow$ & & \\
\hline HFNC & $302(24)$ & $45 / 149(30)$ & $52 / 153(34)$ & & & & \\
\hline Noninvasive vent & $45(4)$ & $10 / 22(46)$ & $6 / 23(26)$ & & & 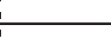 & \\
\hline Invasive vent & $108(9)$ & $19 / 56(34)$ & $21 / 52(40)$ & & & & \\
\hline \multicolumn{2}{|c|}{ Time symptom onset to randomization } & & & 0.81 & & & \\
\hline$<7$ days & $437(35)$ & $55 / 231(24)$ & $61 / 206(30)$ & & $\longrightarrow$ & & \\
\hline \multirow[t]{3}{*}{$\geq 7$ days } & $825(65)$ & $62 / 391(16)$ & $83 / 434(19)$ & & $\longrightarrow$ & & \\
\hline & & & & & 0 & 1 & 2 \\
\hline & & & & & \multicolumn{3}{|c|}{ Odds ratio } \\
\hline
\end{tabular}

Figure 3: Forest plot of relevant subgroups. Note: The $p$ value is from the test of the interaction between the treatment and any subgroup variable. HFNC $=$ high-flow nasal cannulae.

\section{Interpretation}

In the CATCO component of the global WHO Solidarity clinical trial, we found that among 1282 patients admitted with COVID-19 to 52 hospitals in Canada, in-hospital mortality of patients treated with remdesivir was lower than that of control patients.

Table 3: Clinical status on the 10-point World Health

Organization Ordinal Scale for remdesivir, compared with

standard of care in a proportional odds model adjusted for day 1 ordinal scale status*

\begin{tabular}{|lccc|}
\hline Day & Odds ratio & $\begin{array}{c}\text { 95\% confidence } \\
\text { interval }\end{array}$ & $\begin{array}{c}\text { Wilcoxon } \\
\text { rank-sum test } \\
\boldsymbol{p} \text { value }\end{array}$ \\
\hline 3 & 0.88 & 0.71 to 1.08 & 0.1753 \\
\hline 5 & 0.84 & 0.69 to 1.03 & 0.0931 \\
\hline 8 & 0.79 & 0.64 to 0.97 & 0.0232 \\
\hline 11 & 0.78 & 0.63 to 0.97 & 0.0240 \\
\hline 15 & 0.85 & 0.69 to 1.05 & 0.0923 \\
\hline 29 & 0.89 & 0.72 to 1.10 & 0.2580 \\
\hline 60 & 0.91 & 0.73 to 1.14 & 0.4733 \\
\hline *Details in Appendix 1 , at www.cmaj.ca/lookup/doi/10.1503/cmaj.211698/ \\
tab-related-content.
\end{tabular}

Small, regional trials are at high risk of being underpowered to detect modest, but important, treatment effects, and international collaboration is fundamental. At the same time, understanding the role of treatments in different health systems requires careful examination of data to look for region-specific effects, and understanding whether any differences are a result of chance. ${ }^{14}$

Across a range of prespecified subgroups of patients, according to age, sex, degree of respiratory support at admission and duration of symptoms, the odds of in-hospital death were consistent with the main findings among all Canadian patients (Figure 3). The benefit of treatment was most apparent for preventing the need for mechanical ventilation, suggesting probable added value for patients with less severe disease to avoid progression during hospital stay. We found more ventilator- and oxygen-free days among patients receiving remdesivir, as well as improved clinical recovery at day 15, largely consistent with other reported trials, including the Adaptive COVID-19 Treatment Trial (ACTT-1), the trial by Wang and colleagues and Discovery, another substudy of Solidarity. ${ }^{4,15,16}$ This may have important implications for patients and for health systems, particularly when ICU capacity, mechanical ventilation or oxygen are in limited supply.

The findings of CATCO are also important and complementary to Solidarity as they help to address questions of generalizability of a large simple protocol carried out across a wide range of 


\section{Outcome scale at day 15}

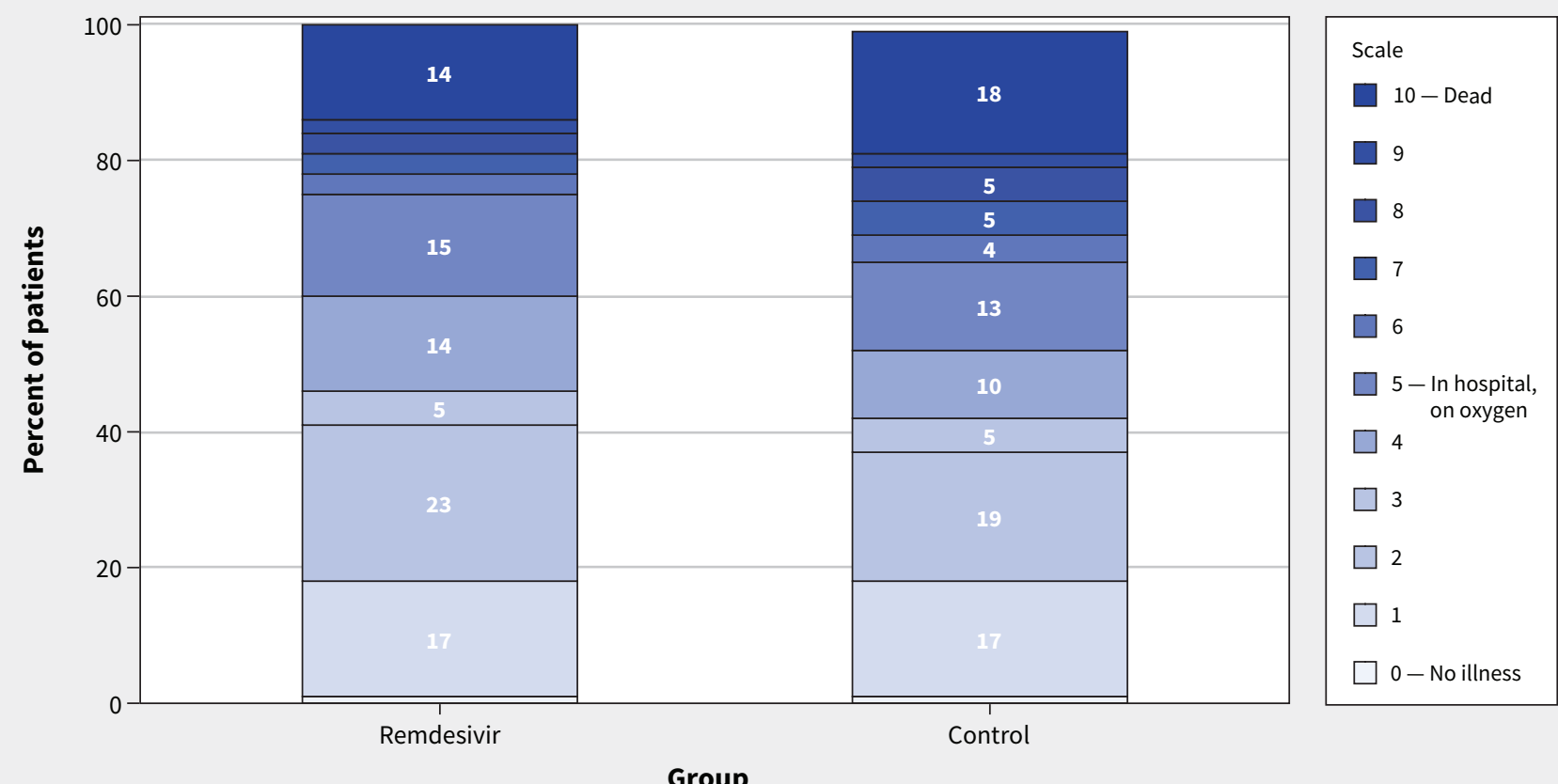

Figure 4: Clinical severity on the World Health Organization Ordinal Scale at day 15 after randomization (0-10, with 10 being death).

hospitals and health care systems from low-, middle- and highincome countries. Canada has a well-developed and relatively resource-rich, nationally regulated and provincially administered system of acute and critical care. ${ }^{17}$ Inpatient hospital care, including medication costs, is typically fully covered by provincial and federal health jurisdictions, with limited to no out-ofpocket costs to patients. Inpatient acute- and critical-care bed supply, although declining in recent years, remains similar to many high-income countries. ${ }^{18,19}$ Accordingly, understanding variability of results across health systems is crucial when considering the relative benefits of drugs that may have small but real benefits.

The CATCO trial was also able to collect more detailed data among enrolled patients than in many global jurisdictions, such as longer follow-up for mortality assessments and incorporation of safety outcomes, and provides generalizable results to other, similar health systems. As well, CATCO was able to continue enrolment of Canadian patients beyond the global trial stop date, resulting in an additional 330 patients who were not reported as part of Solidarity, extending well into Canada's third COVID-19 wave and the emergence of the Alpha variant. This study represents the largest individual country trial of remdesivir yet reported. We were able to include data from several ethnicities, an important component of ensuring generalizability of our results in the Canadian health system, emphasizing the value of recruiting from a wide range of health care facilities. ${ }^{15,20}$
Decision-making on the use of remdesivir in Canada will benefit from an in-progress health economic evaluation comparing the potential effects and costs of the remdesivir treatment evaluated in this trial. Data from small RCTs on the equivalence of 5-day versus 10-day treatment courses should be part of any recommendations on implementation. ${ }^{21}$ Given the high likelihood of heterogeneous treatment effect of remdesivir across the spectrum of severity of disease in patients in hospital, it will be important to thoughtfully steward this therapy.

Understanding differences in risk across different populations and trials, and their impact on the role of remdesivir, will be very important. The control group mortality in CATCO for death by 60 days was $28.2 \%$, compared with $15.2 \%$ in the ACTT-1 cohort by 29 days. ${ }^{16}$ This likely reflects the phase of the pandemic when patients were recruited, baseline severity of illness and a greater focus on recruitment in ICUs, posthospital mortality ${ }^{22}$ and, potentially, associated strain on hospital resources. ${ }^{23}$ Future data syntheses across trials should incorporate these different baseline risks as a potential effect modifier.

\section{Limitations}

This report contains a smaller number of patients than that reported in the main Solidarity trial and, as such, has limited power to independently show statistical significance on the 
primary mortality outcome. The Canadian trial represents outcomes from an intervention delivered in 1 highly resourced health system. Our findings help to understand the expected effects in similar and highly resourced health systems; our data are most consistent with ACTT-1 data.

Information on the infecting variant of SARS-CoV-2 was unavailable at the level of individual patients, so the effect of remdesivir as an antiviral on different variants is impossible to assess; however, the patients in the third wave reported here would likely have been infected with the Alpha variant. ${ }^{24}$ As the pandemic rapidly changed, understanding the impact of varying care over the course of the trial is important; time-based analyses will be considered in future post-hoc analyses. Outcomes such as the use of mechanical ventilation will also be influenced by patient goals of care, and we cannot rule out some imbalance between groups regarding eligibility for mechanical ventilation. A composite of need for intubation and death in those not ventilated at baseline as a post-hoc analysis is included in Appendix 1, Table S3.

Achieving follow-up during a pandemic was often difficult, and we could not contact a proportion of patients for outcome assessment after they were discharged from hospital.

Finally, we did not capture accurate screening data at participating sites, owing to the strain on the health systems during a pandemic, similar to other large-scale pandemic studies. ${ }^{25}$ Given the small number of exclusion criteria, this is unlikely to negatively affect the generalizability of the findings, and the demographic profile of the patients enrolled was similar to the general population of Canadian patients in hospital with COVID-19. ${ }^{26,27}$

\section{Conclusion}

This trial found that in Canadian patients in hospital with COVID19 , remdesivir, in combination with standard care, improved secondary outcomes of need for mechanical ventilation in patients not ventilated at entry, compared with standard care alone, while being underpowered to detect a difference in mortality. Understanding which patient populations would have the largest benefit should be the focus of future meta-analyses.

\section{References}

1. Rochwerg B, Agarwal A, Zeng L, et al. Remdesivir for severe COVID-19: a clinical practice guideline. BMJ 2020;370:m2924.

2. Beigel JH, Tomashek KM, Dodd LE, et al. Remdesivir for the treatment of COVID-19: preliminary report. Reply. N Engl J Med 2020;383:994.

3. WHO Solidarity Trial Consortium; Pan H; Peto R, Henao-Restrepo A-M, et al. Repurposed antiviral drugs for COVID-19: interim WHO solidarity trial results. $N$ Engl J Med 2021;384:497-511.

4. Wang Y, Zhang D, Du G, et al. Remdesivir in adults with severe COVID-19: a randomised, double-blind, placebo-controlled, multicentre trial. Lancet 2020;395:1569-78.

5. Mahajan L, Singh AP, Gifty. Clinical outcomes of using remdesivir in patients with moderate to severe COVID-19: a prospective randomised study. Indian J Anaesth 2021;65(Suppl 1):S41-6.

6. Spinner CD, Gottlieb RL, Criner GJ, et al.; GS-US-540-5774 Investigators. Effect of remdesivir vs standard care on clinical status at 11 days in patients with moderate COVID-19: a randomized clinical trial. JAMA 2020;324:1048-57.
7. Bhimraj A, Morgan RL, Shumaker AH, et al. IDSA guidelines on the treatment and management of patients with COVID-19. Arlington (VA): Infectious Diseases Society of America (IDSA); 2020, updated 2021 Nov. 18. Available: Available: https://www.idsociety.org/practice-guideline/covid-19-guideline -treatment-and-management/ (accessed 2022 Jan. 6).

8. Agarwal A, Rochwerg B, Siemieniuk RA, et al. A living WHO guideline on drugs for COVID-19. BMJ 2020;370:m3379.

9. Lee TC, McDonald EG, Butler-Laporte G, et al. Remdesivir and systemic corticosteroids for the treatment of COVID-19: a Bayesian re-analysis. Int J Infect Dis 2021;104:671-6.

10. Ford I, Norrie J. Pragmatic trials. N Engl J Med 2016;375:454-63.

11. Writing Committee for the REMAP-CAP Investigators; Estcourt LJ, Turgeon AF, McQuilten ZK, et al. Effect of convalescent plasma on organ support-free days in critically ill patients with COVID-19: a randomized clinical trial. JAMA 2021;326:1690-702.

12. WHO Working Group on the Clinical Characterisation and Management of COVID-19 infection. A minimal common outcome measure set for COVID-19 clinical research. Lancet Infect Dis 2020;20:e192-7.

13. Yehya N, Harhay MO, Curley MAQ, et al. Reappraisal of ventilator-free days in critical care research. Am J Respir Crit Care Med 2019;200:828-36.

14. Yusuf S, Wittes J. Interpreting geographic variations in results of randomized, controlled trials. N Engl J Med 2016;375:2263-71.

15. Ader F, Bouscambert-Duchamp M, Hites M, et al.; Discovery Study Group. Remdesivir plus standard of care versus standard of care alone for the treatment of patients admitted to hospital with COVID-19 (DisCoVeRy): a phase 3, randomised, controlled, open-label trial. Lancet Infect Dis 2021 Sept. 14 [Epub ahead of print]. doi: 10.1016/S1473-3099(21)00485-0.

16. Beigel JH, Tomashek KM, Dodd LE, et al.; ACTT-1 Study Group Members. Remdesivir for the treatment of COVID-19: final report. N Engl J Med 2020; 383:1813-26.

17. Naylor CD, Boozary A, Adams O. Canadian federal-provincial/territorial funding of universal health care: fraught history, uncertain future. CMAJ 2020;192: E1408-12.

18. Wunsch H, Angus DC, Harrison DA, et al. Variation in critical care services across North America and Western Europe. Crit Care Med 2008;36:2787-93, e1-9.

19. Adhikari NKJ, Fowler RA, Bhagwanjee S, et al. Critical care and the global burden of critical illness in adults. Lancet 2010;376:1339-46.

20. The Editors; Rubin E. Striving for diversity in research studies. N Engl J Med 2021;385:1429-30.

21. Goldman JD, Lye DCB, Hui DS, et al. Remdesivir for 5 or 10 days in patients with severe COVID-19. N Engl J Med 2020;383:1827-37.

22. Donnelly JP, Wang XQ, Iwashyna TJ, et al. Readmission and death after initial hospital discharge among patients with COVID-19 in a large multihospital system. JAMA 2021;325:304-6.

23. French G, Hulse M, Nguyen D, et al. Impact of hospital strain on excess deaths during the COVID-19 pandemic: United States, July 2020-July 2021. MMWR Morb Mortal Wkly Rep 2021;70:1613-6.

24. Lee J, Lee J, Kim HJ, et al. TMPRSS2 and RNA-dependent RNA polymerase are effective targets of therapeutic intervention for treatment of COVID-19 caused by SARS-CoV-2 variants (B.1.1.7 and B.1.351). Microbiol Spectr 2021;9: e0047221.

25. RECOVERY Collaborative Group; Horby P, Lim WS, Emberson JR, et al. Dexamethasone in hospitalized patients with COVID-19. N Engl J Med 2021;384:693-704.

26. Murthy S, Archambault PM, Atique A, et al.; SPRINT-SARI Canada Investigators and the Canadian Critical Care Trials Group. Characteristics and outcomes of patients with COVID-19 admitted to hospital and intensive care in the first phase of the pandemic in Canada: a national cohort study. CMAJ Open 2021;9:E181-8.

27. Verma AA, Hora T, Jung HY, et al. Characteristics and outcomes of hospital admissions for COVID-19 and influenza in the Toronto area. CMAJ 2021; 193:E410-8. 
Authors: Karim Ali, Tanweer Azher, Mahin Baqi, Alexandra Binnie, Sergio Borgia, François M. Carrier, Yiorgos Alexandros Cavayas, Nicolas Chagnon, Matthew P. Cheng, John Conly, Cecilia Costiniuk, Peter Daley, Nick Daneman, Josh Douglas, Catarina Downey, Erick Duan, Emmanuelle Duceppe, Madeleine Durand, Shane English, George Farjou, Evradiki Fera, Patricia Fontela, Rob Fowler, Michael Fralick, Anna Geagea, Jennifer Grant, Luke B. Harrison, Thomas Havey, Holly Hoang, Lauren E. Kelly, Yoav Keynan, Kosar Khwaja, Gail Klein, Marina Klein, Christophe Kolan, Nadine Kronfli, François Lamontagne, Michael Lau, Todd C. Lee, Nelson Lee, Rachel Lim, Sarah Longo, Alexandra Lostun, Erika MacIntyre, Isabelle Malhamé, Kathryn Mangoff, Marlee McGuinty, Sonya Mergler, Matthew Munan, Srinivas Murthy, Conar O'Neil, Daniel Ovakim, Jesse Papenburg, Ken Kuljit S. Parhar, Seema Nair Parvathy, Chandni Patel, Santiago Perez-Patrigeon, Ruxandra Pinto, Subitha Rajakumaran, Asgar Rishu, Malaika Roba-Oshin, Moira Rushton, Mariam Saleem, Marina Salvadori, Kim Scherr, Kevin Schwartz, Makeda Semret, Michael Silverman, Ameeta Singh, Wendy Sligl, Stephanie Smith, Ranjani Somayaji, Darrell H.S. Tan, Siobhan Tobin, Meaghan Todd, Tuong-Vi Tran, Alain Tremblay, Jennifer Tsang, Alexis Turgeon, Erik Vakil, Jason Weatherald, Cedric Yansouni, Ryan Zarychanski.

Competing interests: Alexandra Binnie reports receiving research grants from the Canadian Institutes of Health Research (CIHR) and the Physicians Services Incorporated Foundation. Sergio Borgia reports receiving honoraria from Gilead Sciences and GSK. Yiorgos Alexandros Cavayas reports receiving a grant from CIHR. Matthew Cheng reports receiving grants from the McGill Interdisciplinary Initiative in Infection and Immunity and from $\mathrm{ClHR}$, during the conduct of the study (payments made to the institution). Dr. Cheng also reports receiving personal fees from AstraZeneca, outside the submitted work; and from Nplex Biosciences and GEn1E lifesciences (in the form of stock options for being a member of the scientific advisory board) outside the submitted work. Dr. Cheng co-founded Kanvas Biosicences and owns equity in the company, and reports 3 patents pending. John Conly reports receiving grants from CIHR, Pfizer, the World Health Organization (WHO), Sunnybrook Research Institute, University of Calgary, and the Calgary Health Foundation. Dr. Conly also reports receiving support to attend the Think Tank Meeting 2019. Dr. Conly is a member and Chair of the WHO Infection Prevention and Control Research and Development Expert Group for COVID-19, a member of the WHO Health Emergencies Programme (WHE) Ad-hoc COVID-19 IPC Guidance Development Group, and a member of the Cochrane Acute Respiratory Infections Group. Madeleine Durand reports receiving grants from CIHR and the Fonds Recherche du Québec-Santé (FRQS). Rob Fowler reports receiving a grant from $\mathrm{CIHR}$ for the CATCO trial and is the $\mathrm{H}$. Barrie Fairley Professor of Critical Care at the University Health Network. Michael Fralick reports receiving multiple grants from CIHR and support from grants from the Canadian military for clinical trials to identify treatments for COVID-19 (payments made to institution). Dr. Fralick is a paid consultant for a start-up company called Proof DiagnosticsDx, which has created a point-of-care testing device using CRISPR for COVID-19. Holly Hoang reports receiving payment from CATCO Sunnybrook to fund research assistant (payment made to institution) and a research grant from Covenant Health Research Centre. Marina Klein reports receiving grants from Gilead, ViiV Healthcare, Merck and AbbVie for investigator-initiated studies, and consulting fees from Gilead, ViiV Healthcare, Merck and AbbVie, all outside the submitted work. Todd Lee reports receiving operating grants from CIHR and McGill Interdisciplinary Initiative in Infection and Immunity (MI4), and research salary support from FRQS. Alexandra Lostun reports receiving per-case funding to cover the costs of enrolling patients (paid to institution, North York General Hospital). François Carrier reports receiving grants from the Instituts de recherche en santé du Canada and the Canadian Donation and Transplantation Research Program, and a grant and salary support from FRQS. Marlee McGuinty reports receiving speaking fees from Merck. Srinivas Murthy reports receiving a grant from CIHR, during the conduct of the study, and is the Health Research Foundation and Innovative Medicines Canada Chair in Pandemic Preparedness Research. Conar O'Neil reports receiving conference sponsorship from Gilead Sciences, and is a member of a Gilead Sciences advisory board. Jesse Papenburg reports receiving a grant from $\mathrm{ClHR}$, during the conduct of the study, as well as research grants and contracts from AbbVie and research contracts (site investigator for clinical trial) from Medlmmune, Merck and Sanofi Pasteur. Dr. Papenburg has received consulting fees from Merck for an ad hoc advisory board meeting, and honoraria for presentations from Seegene, AbbVie and AstraZeneca. Dr. Papenburg is also a voting member of the National Advisory Committee on Immunization. Ken Kuljit S. Parhar reports receiving a CIHR project grant, Alberta Innovates grant and Alberta Health Innovation Implementation and Spread grant (all paid to institution). Seema Nair Parvathy reports receiving funding from St. Joseph's Health Care Foundation and London Health Sciences Foundation. Moira Rushton-Marovac reports receiving advisory board honoraria from Gilead. Marina Salvadori reports being an employee of the Public Health Agency of Canada. Makeda Semret reports receiving support from the McGill MI4 for the clinical research platform through which CATCO was supported at the McGill University Health Centre. Ameeta Singh reports receiving consulting fees from Gilead for membership of an advisory board. Ranjani Somayaji reports receiving contract research funding from Sunnybrook Research Institute, University of Calgary and Calgary Health Foundation, and clinical research funding from $\mathrm{CIHR}$ and the Cystic Fibrosis Foundation. Dr. Somayaji also reports participation on an oncovir data monitoring safety board. Darrell Tan reports receiving grants from AbbVie (in-kind drug only) and Gilead (inkind drug and grants to institution), and a contract between GSK and the institution for clinical trials. Alain Tremblay reports receiving contract research funding from the Sunnybrook Research Institute, and grants for COVID-19 clinical trials from the University of Calgary and Calgary Health Foundation. Alexis Turgeon reports receiving a grant from CIHR. Jason Weatherald reports receiving grants (paid to institution) and consulting fees (paid to Dr. Weatherald) from Janssen and Actelion, as well as honoraria and travel support from Janssen. Dr. Weatherald has served on advisory boards for Janssen and Acceleron (paid) and on a Data Safety Monitoring Board for Université Laval (unpaid). Dr. Weatherald also reports membership of the Medical Advisory Committee of the Pulmonary Hypertension Association of Canada, and is a shareholder of Precision Lung Consultants and Diagnostics. Cedric Yansouni reports receiving grants from FRQS and consulting fees from Medicago Inc. Dr. Yansouni also reports participation in a Medicago Inc. Independent Data Monitoring Committee and held the role of scientific advisor for the COVID-19 Immunity Task Force. No other competing interests were declared.

\section{This article has been peer reviewed.}

Affiliations: Niagara Health (Ali, Tsang), St. Catharines, Ont.; Biomedical Sciences (Azher), Memorial University of Newfoundland, St. John's, Nfld.; William Osler Health System (Baqi, Binnie, Borgia, Havey), Brampton, Ont.; Hôpital du Sacré-Coeur de Montréal (Cavayas), Montréal, Que.; Emergency Department (Chagnon), Montfort Hospital, Ottawa, Ont.; Departments of Pediatrics (Fontela, Papenburg), Surgery and Critical Care Medicine (Khwaja), McGill University, Montréal, Que.; Divisions of Infectious Diseases (Cheng, Costiniuk, Harrison, M. Klein, Kronfli, T. Lee, Semret, Yansouni), Chronic Viral Illness Service (Costiniuk, M. Klein), Medical Microbiology (Cheng, Yansouni), Internal Medicine (Malhamé, T. Lee), and Infectious Diseases and Immunity in Global Health Program (M. Klein, Kronfli, T. Lee, Papenburg) McGill University Health Centre, Montréal, Que.; Division of Respirology (Lim, Weatherald), Cumming School of Medicine (Conly, Somayaji), and Departments of Critical Care Medicine (Parhar), Repiratory Medicine (Tremblay) and Interventional Pulmonary Medicine (Vakil), University of Calgary, Calgary, Alta.; Health Sciences Centre (Tremblay), University of Calgary, Calgary, Alta.; Discipline of Laboratory Medicine (Daley), Memorial 
University of Newfoundland, St. John's, Nfld.; Lion's Gate Hospital (Douglas), Vancouver, BC; CCTS at Sunnybrook Research Institute Centre for Clinical Trial Support (Downey, G. Klein, Lau, Longo, Mangoff, Mergler, Patel, Rajakumaran, Roba-Oshin, Saleem, Tobin, Todd), Toronto, Ont.; Departments of Medicine and Critical Care Medicine (Fowler) and Division of Infectious Diseases (Daneman), Sunnybrook Hospital, Toronto, Ont.; Department of Critical Care Medicine (Pinto, Rishu), Sunnybrook Health Sciences Centre, Toronto, Ont.; Division of Critical Care (Duan), Department of Medicine (Tsang), McMaster University, Hamilton, Ont.; Departments of Anesthesiology (Carrier), Medicine (Duceppe, Kolan), Intensive Care Medicine (Carrier) and Internal Medicine (Duceppe, Kolan) and Internal Medicine Service (Durand), Centre Hospitalier de l'Université de Montréal (CHUM), Montréal, Que.; Departments of Medicine (English) and Infectious Diseases (McGuinty), The Ottawa Hospital, Ottawa, Ont.; Department of Medicine (English), Ottawa Hospital Research Institute, Ottawa, Ont.; Niagara Health (Farjou, Tsang), St. Catharines, Ont.; Markham Stouffville Hospital (Fera), Markham, Ont.; Division of General Internal Medicine (Fralick), Department of Medicine, Sinai Health System; Department of Medicine and Critical Care Medicine (Geagea, Lostun), North York General Hospital, Toronto, Ont.; Departments of Pediatrics (Murthy) and Pathology and Laboratory Medicine (Grant), Faculty of Medicine, University of British Columbia, Vancouver, BC; Island Health Authority (Ovakim), University of British Columbia, Vancouver, BC; Division of Infectious Diseases (Hoang), Department of Medicine, Grey Nuns Community Hospital, Edmonton, Alta.; Department of Pharmacology and Therapeutics (Kelly), George and Fay Yee Centre for Healthcare Innovation, University of Manitoba; Departments of Infectious Disease and Medical Microbiology (Keynan) and Internal Medicine (Zarychanski), University of Manitoba, Winnipeg, Man.; Centre intégré universitaire de santé et de services sociaux de l'Estrie - Centre Hospitalier Universitaire de Sherbrooke (Lamontagne), Sherbrooke, Que.; Departments of Critical Care (MacIntyre, Sligl) and Medicine (Singh, Smith), Division of Infectious Diseases (O'Neil), University of Alberta, Edmonton, Alta.; Department of Critical Care Medicine (Munan), Misericordia Community Hospital, Edmonton, Alta.; Misericordia Hospital - Covenant Health (Scherr), Edmonton, Alta.; St. Joseph's Health Care (Parvathy), London, Ont.; Department of Medicine (Perez-Patrigeon), Queen's University, Kingston, Ont.; Queensway Carleton Hospital (Rushton), Nepean, Ont.; Public Health Agency of Canada (Salvadori), Ottawa, Ont.; Unity Health Toronto (Schwartz), Toronto, Ont.; Dalla Lana School of Public Health
(N. Lee, Schwartz), University of Toronto, Toronto, Ont.; Department of Medicine (Silverman), Western University, London, Ont.; Division of Infectious Diseases (Tan), St. Michael's Hospital, Toronto, Ont.; Department of Anesthesiology and Critical Care Medicine (Turgeon, Tran), CHU de Québec-Université Laval, Québec, Que.

Association of Medical Microbiology and Infectious Disease Canada (AMMI) Clinical Research Network, and the Canadian Critical Care Trials Group: Barbara Antuna-Puente, Eneko Arhanchiague, Pascale Arlotto, Zeeshan Aslam, Fiona Auld, David Bellemare, Isaac Bogoch, Vikas Chaubey, Ėve Cloutier, William Connors, Olivier Costerousse, Giulio DiDiodato, Charlene Fell, Greg Gamble, Stephen Giilck, Galo Ginocchio, Stephanie Go, Christopher Graham, Kaveri Gupta, Brent Guy, Amila Heendeniya, Susan John, Christopher Kandel, Anthony Ladelfa, François Lellouche, Allison Mah, Karen Mandelzweig, Sanjay Manocha, Caitlyn Marek, Rosa Myrna Marticorena, Stephanie Matte, Marc MessierPeet, Patrick Mitchell, Elliott Owen, Elizabeth Parfitt, Lisa Patterson, Shaqil Peermohamed, Germain Poirier, Susan M. Poutanen, Jeff Powis, Natasha Press, Valerie Sales, Maureen Taylor.

Data sharing: All of the individual participant data collected during the trial, after deidentification, will be available to external groups upon scientific review. Proposals should be sent to catco@sunnybrook.ca.

Acknowledgements: This trial was generously supported by the Canadian Institutes of Health Research, the Vancouver Coastal Health Research Institute, the Northern Alberta Clinical Trials and Research Centre, Covenant Health Research Centre, the McGill Interdisciplinary Initiative in Infection and Immunity, the St. Joseph's Health Care Foundation, and the London Health Sciences Foundation. The authors thank Mark Duffett for critical appraisal of this manuscript, and peer reviewers at CMAJ who markedly improved this report.

Content licence: This is an Open Access article distributed in accordance with the terms of the Creative Commons Attribution (CC BY-NC-ND 4.0) licence, which permits use, distribution and reproduction in any medium, provided that the original publication is properly cited, the use is noncommercial (i.e., research or educational use), and no modifications or adaptations are made. See: https://creativecommons.org/ licenses/by-nc-nd/4.0/

Accepted: Dec. 20, 2021

Correspondence to: Srinivas Murthy, srinivas.murthy@cw.bc.ca 